\title{
SOJICULTURA E MERCADO DE TERRAS NA AMAZÔNIA ${ }^{1}$
}

\section{Solange Maria Gayoso da Costa}

Universidade Federal do Pará (UFPA)

\section{SOJICULTURA E MERCADO DE TERRAS NA AMAZÔNIA}

Resumo: Este artigo apresenta os resultados obtidos na pesquisa sobre a relação da sojicultura com o mercado de terras na Amazônia, com recorte de pesquisa nos municípios que compõem a região do Baixo Amazonas, usando como procedimentos metodológicos o levantamento bibliográfico e estatístico, acrescido de pesquisa de campo e levantamento de dados dos imóveis rurais registrados junto ao Cartório do $1^{\circ}$ Oficio de Santarém-Pará, no período de 1997 a 2009. Conclui que o volume de áreas plantadas, em parte, foi composto pela negociação de imóveis abaixo de 100 ha que, em sua totalidade, correspondem a Títulos de Reforma Agrária emitidos pelo INCRA, agravando, assim, a concentração de terras rurais na região.

Palavras-chave: Sojicultura, mercado de terras, Amazônia.

\section{SOYBEAN PRODUCTION AND MARKETING OF LANDS IN AMAZON}

Abstract: This paper presents the results obtained in the research on the relationship of soybean production and the land market in the Baixo Amazonas River region, using as methodological procedures the bibliographic and statistical survey, plus with field research and survey data of rural properties registered with the Registry of the 1ST Notary of Santarém-Pará, in the period 1997 to 2009 . It is concluded that the volume of planted areas, in part, was composed by negotiation of buildings below 100 ha, which in its totality corresponding to Titles issued by INCRA, aggravating the concentration of rural land in the region.

Key words: Soybean production, land market, Amazon. 


\section{INTRODUÇÃO}

0 acentuado e contínuo crescimento do agronegócio de grãos destinado à exportação tem favorecido o saldo da balança comercial brasileira, sobretudo pela elevação dos preços das principais commodities no mercado internacional, com aumento de sua participação na pauta do comércio exterior, conferindo ao Brasil o status de um dos principais exportadores de produtos e tecnologias de produção de grãos.

Atualmente, dezessete estados brasileiros e o Distrito Federal mantêm produção de soja: Roraima, Amazonas, Pará e Tocantins, na Região Norte; Maranhão, Piauí, Ceará e Bahia, na Região nordeste; Minas Gerais e São Paulo, na Região Sudeste; Mato Grosso, Mato Grosso do Sul, Goiás e o Distrito Federal, na Região Centro-Oeste; Paraná, Santa Catarina e Rio Grande do Sul, na Região Sul. $O$ desenvolvimento da produção nessas Unidades da Federação resultou em um expressivo aumento da área plantada a partir da safra 1991, passando de 9,5 milhões de hectares para 27,7 milhões de hectares na safra 2013.

Esse crescimento exponencial nas duas últimas décadas gerou expectativas de que o Brasil venha a ser um dos mais competitivos países ofertantes de bens agropecuários do mundo, desde que supere as dificuldades de logística, que oneram os custos do escoamento da produção de grãos. Constitui-se, ainda, em um fator decisivo para que esse crescimento se mantenha; a área disponível para a expansão agrícola no país é estimada pelo Ministério da Agricultura entre 90 a 106 milhões de hectares.

As projeções oficiais indicam que a área destinada ao plantio de soja deve abranger 30,0 milhões de hectares em 2020/2021, representando um acréscimo de 5,3 milhões de hectares em relação à 2010/2011, com estimativa de crescimento de 1,9\% ao ano. A soja deve manter essa tendência, por meio de uma combinação de expansão da fronteira em regiões onde ainda há terras disponíveis, ocupação de terras de pastagens e pela substituição de lavouras (BRASIL, 2011).

A Amazônia, em decorrência do volume de terras aráveis, que, segundo o Empresa Brasileira de Planejamento de Transportes (GEIPOT) (1999), tem 22 milhões de hectares, e da sua posição estratégica para o escoamento da produção, tem sido considerada uma fronteira agrícola imprescindível para o crescimento do agronegócio de grãos. Um fator que influenciou para a rápida expansão das lavouras de soja nos estados amazônicos foi o grande estoque de terras, comercializadas a preços bastante inferiores àqueles praticados em regiões de plantação já consolidadas.

Na Amazônia Legal2 , o volume de área plantada, que em 1990 era de 1.602 .975 hectares, passou para 8.223.381 hectares em 2012 (IBGE, 1990-2012). Segundo os dados do IBGE, na década de 2000, dos nove estados localizados na Amazônia Legal, apenas no estado do Amapá não foi registrada a produção de soja.

Neste artigo discute-se a expansão das áreas plantadas de soja na Amazônia, tendo como referência de análise a implantação da sojicultura na região do Baixo Amazonas, uma área de $317.273,50 \mathrm{~km}^{2}$, composta por 13 municípios: Alenquer, Almeirim, Belterra, Curuá, Faro, Juruti, Monte Alegre, Óbidos, Oriximiná, Placas, Prainha, Porto de Moz, Santarém, Mojuí dos Campos ${ }^{3}$ e Terra Santa, que sofreu um processo de intensas mudanças e conflitos provocados pela chegada da sojicultura.

Este artigo busca desenvolver argumentos acerca da estreita relação estabelecida entre a expansão da sojicultura, 0 aquecimento das negociações e a concentração de terras na Amazônia, a partir da pesquisa de imóveis registrados junto ao Cartório do $1^{\circ}$ Ofício do município de Santarém (PA), no período de 1997 a 2009, acrescido de pesquisa de campo, com a realização de entrevistas junto a lideranças sindicais e produtores de soja. 


\section{A PRODUÇÃO DE SOJA NA AMAZÔNIA}

A expansão da soja para os estados nortistas da Amazônia Legal toma como referência o modelo adotado na Região Centro-Oeste, mais especificamente no Estado do Mato Grosso. A produção de soja no Centro-Oeste se desenvolveu em médias e grandes propriedades, por meio da utilização de técnicas modernas de produção, diferente da Região Sul do país, onde pequenos produtores participam da cadeia produtiva.

A produção da soja na Amazônia Legal apresenta um crescimento exponencial a partir da década de 1990, conforme pode ser observado na Tabela 1. Até 1990 havia 1.602 .975 hectares de terras utilizados em plantios de soja, em quatro estados: Maranhão, Mato Grosso, Roraima e Tocantins. No ano de 2012, a área plantada já era de 8.223.381 hectares, envolvendo sete estados da Amazônia Legal: Amazonas, Maranhão, Mato Grosso, Pará, Rondônia, Roraima e Tocantins.

Cotejando os dados sobre a área plantada e o número de estabelecimentos rurais existentes nos estados plantadores de soja, foi possível observar que em todos os estados da Amazônia Legal, na década de 1990, há um decréscimo do número de imóveis rurais menores que 100 hectares, e um crescimento de imóveis entre 100 e 1000 hectares (Tabela 2), 0 que pode indicar uma estratégia de composição de uma propriedade rural a partir da aquisição de vários imóveis com áreas menores de 100 hectares por um único proprietário4.

A relação entre a expansão da sojicultura e a concentração de terras é mencionada em diversos estudos. Costa (2000) identificou que no Mato Grosso, em 1980, 37\% da produção

Tabela 1 - Soja - área plantada (em hectares) por estados da Amazônia Legal e Brasil

\begin{tabular}{lccrrrr}
\hline & 1990 & $\mathbf{1 9 9 5}$ & $\mathbf{2 0 0 0}$ & $\mathbf{2 0 0 5}$ & $\mathbf{2 0 1 0}$ & $\mathbf{2 0 1 2}$ \\
\hline Brasil & 11.584 .734 & 11.702 .919 & 13.693 .677 & 23.426 .756 & 23.339 .620 & 25.090 .559 \\
Amz. Legal & 1.602 .975 & 2.451 .353 & 3.158 .368 & 7.008 .094 & 7.285 .548 & 8.223 .381 \\
AC & - & - & - & 55 & 100 & - \\
AP & - & - & - & - & - & - \\
AM & - & - & 1.060 & 2.256 & 180 & 220 \\
MA & 15.305 & 87.690 & 178.716 & 372.074 & 495.756 & 556.178 \\
MT & 1.552 .910 & 2.338 .926 & 2.906 .648 & 6.121 .724 & 6.227 .044 & 6.980 .690 \\
PA & - & - & 2.225 & 68.410 & 85.450 & 119.686 \\
RO & 4.640 & 4.500 & 11.800 & 75.275 & 122.743 & 146.144 \\
RR & - & - & - & 13.000 & 1.400 & 5.000 \\
TO & 30.120 & 20.237 & 57.919 & 355.300 & 352.875 & 415.463 \\
\hline
\end{tabular}

Fonte: INSTITUTO BRASILEIRO DE GEOGRAFIA E ESTATÍSTICA. Banco de Dados Agregados. Rio de Janeiro, [20--?]. Disponível em:<http://www.sidra.ibge.gov.br/bda.>Acesso em: 25 ago. 2011.

Tabela 2 - Número de estabelecimentos rurais por tamanho do imóvel nos estados produtores de soja na Amazônia Legal

\begin{tabular}{|c|c|c|c|c|c|c|c|c|}
\hline & \multicolumn{2}{|c|}{ Total de imóveis } & \multicolumn{2}{|c|}{$\begin{array}{c}>100 \text { (ha) } \\
\%\end{array}$} & \multicolumn{2}{|c|}{$\begin{array}{c}100>1000 \text { (ha) } \\
\%\end{array}$} & \multicolumn{2}{|c|}{$\begin{array}{c}>1000 \text { (ha) } \\
\%\end{array}$} \\
\hline & 1996 & 2006 & 1996 & 2006 & 1996 & 2006 & 1996 & 2006 \\
\hline$A C$ & 23.788 & 29.4822 & 21,16 & 19,2 & 39,2 & 47,77 & 39,64 & 33,03 \\
\hline AM & 83.289 & 66.784 & 34,42 & 24,61 & 29,38 & 33,00 & 36,20 & 42,38 \\
\hline MA & 368.191 & 287.037 & 22,24 & 21,50 & 41,41 & 42,38 & 36,35 & 36,12 \\
\hline MT & 78.762 & 112.978 & 3,28 & 5,52 & 14,52 & 16,96 & 82,20 & 77,51 \\
\hline PA & 206.404 & 222.028 & 19,22 & 18,38 & 29,91 & 32,48 & 50,87 & 49,14 \\
\hline RO & 76.956 & 87.077 & 21,46 & 26,84 & 31,20 & 39,29 & 47,34 & 33,87 \\
\hline RR & 7.476 & 10.310 & 6,0 & 22,78 & 20,3 & 31,76 & 73,7 & 45,46 \\
\hline TO & 44.913 & 56.567 & 5,41 & 9,21 & 37,49 & 33,53 & 57,09 & 57,27 \\
\hline
\end{tabular}

Fonte: INSTITUTO BRASILEIRO DE GEOGRAFIA E ESTATÍSTICA. Censo agropecuário 2006. Rio de Janeiro, 2007. 
vinha de propriedades com 100 hectares ou menos, enquanto $25 \%$ de propriedades superiores a 1.000 hectares. Já em 1985, apenas $20 \%$ da produção pertencia ao primeiro grupo e $45 \%$ ficavam com as grandes propriedades.

No Maranhão, segundo Miranda (2010), os anos de 1990 foram marcados por intenso processo de concentração de terras e de violentos conflitos entre especuladores de terras, sojicultores, trabalhadores rurais, lideranças sindicais e membros das igrejas Católica e Luterana.

No estado do Tocantins, Castilho e Castro (2005) identificaram um processo intenso de deslocamento de pequenos agricultores para a periferia da área urbana de Campos Lindos, com a chegada de produtores de soja e a instalação das empresas multinacionais Cargill, Bunge, Multigreen e Agrenco, que fornecem crédito aos produtores de soja, sob a forma de compra antecipada.

No estado do Amazonas, Lima (2008) menciona que, apesar do processo de concentração fundiária não ser recente na região, ao longo da década de 1990, e na década seguinte, apresentou trajetória ascendente. Na região sul do estado, os dados do INCRA apresentados pela autora mostraram que

[...] $17 \%$ do número dos imóveis rurais desse território são de médias e grandes propriedades que representam $96 \%$ dos imóveis cadastrados. (LIMA, 2008, p. 284).

No Pará, Gayoso da Costa (2012), observando os dados do levantamento da produção agrícola do IBGE entre os anos de 1997 a 2010, identificou o crescimento do cultivo da soja, pela incorporação de novas áreas. No ano de 2012, treze anos depois das primeiras experiências, dezessete munícipios já possuem plantios, ocupando uma área total de 119.686 hectares, dentre os quais se incluem os municípios do Baixo Amazonas, onde também houve um intenso processo de deslocamento de pequenos produtores e conflitos agrários.

\subsection{Achegada da produção de soja no Baixo Amazonas}

A produção da soja na região do Baixo Amazonas ocorreu a partir de investimentos privados, estimulados pela ação interventiva e programática da esfera estatal. Considerando a ação prevista no Polo Agroindustrial para a região Oeste do estado, o governo do Pará, em 1996, antecipando um possível asfaltamento da BR-163, contratou a Agrária Engenharia Consultoria S.A. para estudar a viabilidade da agricultura empresarial no polo Santarém. Seguindo as recomendações desta consultoria, implantou um projeto piloto de cultivo de soja na área do cerealista e pecuarista Francisco Quincó na PA-370, rodovia Santarém-Curuá-Una (COMISSÃO PASTORAL DA TERRA, 2004; PUTY, 2007).

Após os primeiros resultados, e munidos dos estudos do zoneamento agroecológico, técnicos do governo e empresários de Santarém viajaram para o Mato Grosso, a fim de divulgar o potencial agrícola da região, para atrair os grandes produtores de grãos. Em 1997, começaram a chegar sojicultores à região; primeiro os pequenos e médios produtores, que migraram do Sul do país, do estado de Mato Grosso e de Roraima. Foram arrendadas terras do próprio Francisco Quincó, além de aquisições de lotes de agricultores familiares. Naquele ano, o preço da terra na PA-370 e nos municípios de Santarém e Belterra variava entre $R \$ 200,00$ e $R \$ 300,00$ o hectare. As primeiras plantações foram de milho e arroz, e após o período de dois anos foi iniciado o plantio da soja, em regime de rotação com aquelas culturas, além do sorgo e do milheto ${ }^{5}$.

De acordo com as estimativas da prefeitura de Santarém, em 2004, o município tinha entre 500 a 600 mil hectares de floresta antropizada, aptos para 0 uso agrícola (PUTY, 2007). Em 2005, Almeida e outros (2006), em pesquisa sobre arranjos produtivos locais, identificou a existência de 340 produtores. Em 2012, eram 205 cadastrados no programa de monitoramento da Cargill (GAYOSO DA COSTA, 2012). Relatos de lideranças sindicais apontaram para esta queda e 
suas diferentes causas. Os sindicalistas vinculados ao Sindicato de Trabalhadores e Trabalhadoras Rurais (STTR) estabelecem uma relação direta entre o processo e o resultado das pressões internacionais contra o desmatamento causado pelo plantio da soja na região, que resultou na assinatura da moratória da soja, prejudicando o financiamento da produção, e estimulou a partida de muitos da região: "[...] eram carretas e carretas com máquinas na SantarémCuiabá, saindo de Santarém." (Informação verbal) ${ }^{6}$. Já os sindicalistas vinculados ao Sindicato dos Produtores Rurais (SIRSAN) acrescentam a essa causa anterior, o prejuízo financeiro dos pecuaristas, donos de grandes extensões de terras, que se aventuraram no plantio de soja quando da queda dos preços ocorrida durante a safra de 2004/20057.

Entrevistas com lideranças sindicais em Santarém indicaram que os plantios da soja na região do Baixo Amazonas foram desenvolvidos nos municípios de Santarém e Belterra, Monte Alegre, Alenquer, Óbidos e Prainha. Contudo, no levantamento sistemático da produção agrícola realizado pelo IBGE, não constam informações sobre a produção no município de Prainha e Óbidos.

Os dados sobre a produção agrícola nos municípios do Baixo Amazonas sinalizam também a diminuição da área plantada nos anos de 2006 e 2007, havendo uma recuperação nos anos posteriores, chegando em 2012 com 29.820 hectares utilizados nos plantios de soja, conforme demonstrado na Tabela 3. Isso nos leva a afirmar que os produtores que permaneceram na região superaram a crise desencadeada pela queda dos preços da soja nos anos de 2004/2005, mantendo uma estabilidade na produção nos anos seguintes.

Santarém e Belterra são os dois municípios com maior volume de terras ocupadas com plantio de soja, por consequência, respondem por $96 \%$ da produção local. Os primeiros produtores de grãos tiveram apoio da esfera estatal, principalmente da prefeitura de Santarém, bem como da Associação Comercial. Os custos dessas primeiras plantações foram cobertos pelos próprios produtores. Segundo Puty (2007), o Fundo Constitucional de Financiamento do Norte (FNO) financiou a produção de grãos no município somente a partir da safra 1999/2000. Coincidentemente, ou melhor, estrategicamente, foi nesse período que teve início a construção do porto da empresa exportadora de grãos Cargill, o que atraiu 0 interesse de grandes produtores de grãos do Mato Grosso.

Em 2003, tem-se o que se convencionou chamar de segunda onda de invasão da soja na região santarena, quando chegaram grandes produtores, ocupando áreas de terras devolutas ao leste, na gleba Pacoval; e ao sul, no Projeto de Assentamento Mojuí I e II, no planalto santareno. Parte dessas áreas era de floresta primária, e demarcada em lotes maiores que a média, ou seja, acima de 2.500 hectares (COMISSÃO PASTORAL DA TERRA, 2004). Simultaneamente, iniciou-se um intenso comércio ilegal de terras, acompanhado de ações violentas contra pequenos agricultores familiares, nas áreas de maior especulação.

Tabela 3 - Área plantada de soja (em hectares) por município, na região do Baixo Amazonas (2004-2012)

\begin{tabular}{lccccccccc}
\hline $\begin{array}{l}\text { Anol } \\
\text { Município }\end{array}$ & $\mathbf{2 0 0 4}$ & $\mathbf{2 0 0 5}$ & $\mathbf{2 0 0 6}$ & $\mathbf{2 0 0 7}$ & $\mathbf{2 0 0 8}$ & $\mathbf{2 0 0 9}$ & $\mathbf{2 0 1 0}$ & $\mathbf{2 0 1 1}$ & $\mathbf{2 0 1 2}$ \\
\hline $\begin{array}{l}\text { Alenquer } \\
\text { Belterra }\end{array}$ & $\mathbf{4 7 5}$ & 600 & 600 & - & - & - & - & - & - \\
Curuá & 5.000 & 13.500 & 8.000 & 10.000 & 15.000 & 10.150 & 11.400 & 11.800 & 11.800 \\
Monte Alegre & 100 & 100 & - & - & - & - & - & - & - \\
Placas & $(-)$ & $(-)$ & 35 & $-(-)$ & 160 & 80 & 80 & 220 & 220 \\
Santarém & 11.000 & 22.000 & 19.500 & 15.000 & 17.250 & 18.000 & 17.100 & 17.800 & 17.800 \\
TOTAL & 16.975 & 36.600 & 28.135 & 25.000 & 32.410 & 28.230 & 28.580 & 29.820 & 29.820 \\
\hline
\end{tabular}

Fonte: PARÁ. Secretaria Estadual de Desenvolvimento Agropecuário e de Pesca. Dados Agropecuários. Belém, 2012. Disponível em:<http://www.sagri.pa.gov.br/>. Acesso em: 21 nov. 2011. 
O processo de especulação fundiária provocou o deslocamento de muitas famílias para a área urbana da cidade de Santarém, como também a fuga para áreas de terras devolutas ou para regiões mais afastadas das principais rodovias, como o Projeto de Assentamento Cota Corda, onde posteriormente também foram atingidas pelos conflitos gerados pelas disputas de terras. O STTR estimou que cerca de 500 famílias foram deslocadas de suas terras, em decorrência da implantação da soja na região. A chegada da sojicultura provocou uma violenta valorização das terras e intensificou a concentração fundiária, como apresentaremos mais adiante.

\section{SOJICULTURA E MERCADO DE TERRAS NA AMAZÔNIA}

A dinâmica do mercado de terras na Amazônia tem como base uma estrutura fundiária que, segundo Costa (2011), apresenta quatro características: alto grau de assimetria distributiva; permite a formação estratégica de estoques de ativos de existência finita; admite tratamento indistinto de ativos distintos; e suporta o uso dos recursos públicos por critérios privados, ou seja, permite a grilagem de terras. Combinadas, essas características da estrutura fundiária fundamentam o mercado de terras que, segundo o referido autor, se expressa nos preços e na natureza do que movimentam. Com base na pesquisa anual da FNP (Agra FNP Pesquisas Ltda.) nos estados do Acre, Amapá, Amazonas e Pará, Costa (2011) aponta três grandes categorias da terra mercadoria: Terras com Mata, Terras de Pastagem e Terras de Lavoura. Dentre essas, os preços das Terras com Matas são parcelas das demais. Isso que dizer que, para o mercado, as Terras com Matas são consideradas como componentes de formação de preços das pastagens e das terras agrícolas, num tipo de regulação que não inviabilize a transformação das Terras com Matas em Terras de Pastagens e Terras de Lavoura, como podemos observar no processo de incorporação de terras na região do Baixo Amazonas a partir da chegada da soja, onde as áreas com matas serviram como capitalização para a instalação das lavouras de grãos.

Analisando os dados dos Censos Agropecuários de 1995 e 2006, Costa (2011) identificou que, em onze anos, os operadores dos estabelecimentos rurais adquiriram 5,4 milhões de hectares de Terras para Lavoura, 8,2 milhões de Terras de Pastagem e 0,5 milhões de hectares adicionais aos seus estoques de Terra com Mata. Costa (2011) chegou à conclusão de que o estrato que mais se apropriou do estoque de terras foram os estabelecimentos patronais que convergiram para a pecuária de corte, chegando, no ano de 2006, ao percentual de $39,6 \%$, entre reservas de matas e 0 total apropriado por todos os estabelecimentos. 0 autor conclui que 11,3 milhões de hectares de florestas originárias foram transformados em terras ocupadas pelo estrato patronal voltado à pecuária de corte $^{8}$.

A redução das florestas originárias a terras destinadas à oferta de Terras de Pastagens e Terras de Lavoura pressupõe uma adequação dos custos, de acordo com a atividade a que se destinam. $\mathrm{O}$ autor afirma que isso é possível pelas condições institucionais vigentes, que, de um lado igualam os ativos distintos - terra e bioma, e de outro garante a sistemática institucional (patrimonialista) de apossamento privado da coisa pública. Tais processos são operacionalizados pelo mecanismo da grilagem. A grilagem, mais do que uma questão ética, firmou-se como mecanismo de evolução de um determinado estrato, como modus operandi de agentes e organizações que processam uma "[...] economia com leis próprias de estruturação e movimento." (COSTA, 2011, p. 340).

Pesquisas sobre desmatamento e pecuária (CASTRO, 2007; CASTRO; MONTEIRO; CASTRO, 2002; CASTRO; MONTEIRO, 2007), sojicultura e mercado de terras (GAYOSO DA COSTA, 2012), demonstraram a intensa relação entre a transformação de florestas originárias em terras, em que a exploração madeireira serviu para a capitalização monetária e financeira, constituindose, logo depois, em Terra de Pastagem, para 
posteriormente transformar-se, toda ou em parte, em Terras de Lavoura. No caso da região do Baixo Amazonas, observou-se que a essa dinâmica agrega-se outra, que suprime a constituição da Terra de Pastagem. Ou seja, passa-se da transformação das florestas originárias em terras, para Terras de Lavoura.

O mercado de terras na Amazônia estabelece preços para os três tipos de mercadoria: Terras com Mata, Terras de Pastagem e Terras de Lavoura. Desde meados da década de 1990, quando se iniciaram os experimentos com a produção de soja, as terras na mesorregião do Baixo Amazonas sofreram aumento nos preços. Naquele ano, o preço da terra na PA-370 e no município de Belterra, locais em que foram instaladas as primeiras áreas de agricultura mecanizada, era de $R \$ 200,00$ e $R \$ 300,00$ o hectare. A partir de 2000/2003, com o aumento da migração dos produtores de soja, segundo as estimativas da Empresa de Assistência Técnica e Extensão Rural do Estado do Pará (EMATER, 2006 apud PUTY, 2007), o preço da terra passara de $R \$$ $300,00 /$ ha para ate $R \$ 3.000,00 /$ ha no município de Santarém, com uma variação percentual de 1.500\% de aumento do preço da terra.

Lideranças sindicais dos trabalhadores rurais apontaram um incremento no preço da terra bem superior àquele apresentado por Puty (2007), com preços variando entre $R \$ 30,00$ o hectare em 1999, para $R \$ 15.000,00$ nos anos de 2005/2006, uma variação percentual de $75.000 \%$ no aumento, em menos de dez anos. Ainda que os dados possam ser questionados, o que importa ressaltar é a variação no aumento do preço da terra, que indica um mercado de terras extremamente aquecido com a chegada dos sojicultores, gerando lucros altíssimos para os especuladores e grileiros de terras.

Pesquisa sobre o mercado de terras no Brasil, feita pela empresa Informa Economics South American (FNP) 9 , apontou que as valorizações relativas registradas no ano de 2010 estão nas áreas de mata, terras agrícolas, caatingas e pastagens, nos estados do Pará, Rondônia, Amazonas, Mato Grosso, Paraíba e Piauí. Tais variações relativas ocorrem principalmente porque os preços iniciais são muito baixos, como no caso do Baixo Amazonas, o que gera aumentos percentuais elevados. A empresa indica que há uma forte valorização do mercado madeireiro, assim como o manejo florestal tem servido para valorizar essas áreas de mata.

Segundo os dados da Informa Economics América South-FNP (2011), as áreas destinadas à produção de grãos mais valorizadas no ano de 2010 estão nas regiões de Santarém, no Pará, com 88 a $111 \%$ de valorização, seguido da região de Balsas, no Maranhão, com valorizações de até $55 \%$. 0 preço do hectare em Santarém era de $\mathrm{R} \$ 475,00$ em março-abril/2010, chegando a $R \$ 1000,00$ em o preço do hectare ficava em $R \$ 4.200,00$ em 2010, chegando ao valor de $\mathrm{R} \$ 6.500,00$ no ano de 2011. Nota-se que o crescimento da produção de soja tem mantido a valorização das terras na Amazônia Legal, notadamente naquelas regiões cuja produção de grãos pode ser considerada estabilizada e que possuem melhor infraestrutura de escoamento, onde o preço da terra fica ainda mais elevado. Outro fator de influência é a sua condição de mecanizável ou não. Tais variações podem ser observadas na Tabela 4.

Ao examinar os dados da Tabela 4, identifica-se a valorização das terras de pastagem formada, que podem ser mecanizadas, e a terra agrícola em Santarém, Belterra, Monte Alegre, Alenquer e Oriximiná, municípios da região do Baixo Amazonas, o que reforça o interesse do mercado de terras nessa região. Pode-se verificar também que as terras de matas próximas à $B R$ têm seu preço equivalente às terras agrícolas, enquanto que aquelas áreas de matas distantes das principais rodovias de escoamento da produção apresentam um preço inferior a $50 \%$, em média.

\subsection{Vendas de terras e sojicultura no Baixo Amazonas}

A dinâmica do mercado de terras, em parte, pode ser identificada a partir dos registros cartoriais de imóveis rurais. No levantamento realizado nos 
Tabela 4 - Preço da terra por tipos, na região de Santarém (2010-2011)

\begin{tabular}{lrr}
\hline Tipo de Terra & $\mathbf{2 0 1 0}$ (R\$/ha) & $\mathbf{2 0 1 1}$ (R\$/ha) \\
\hline Mata (Monte Alegre/Alenquer/Oriximiná) distante da BR & 220 & 400 \\
Mata (Monte Alegre/Alenquer/Oriximiná) próxima à BR & 450 & 500 \\
Mata (Santarém/Belterra/Transamazônica) distante da BR & 350 & 500 \\
Mata (Santarém/Belterra/Transamazônica) próxima à BR & 750 & 1.000 \\
Pastagem formada (Monte Alegre/Alenquer/Oriximiná) mecanizável & 450 & 900 \\
Pastagem formada (Monte Alegre/Alenquer/Oriximiná) não mecanizável & 400 & 550 \\
Pastagem formada (Santarém/Belterra/Transamazônica) mecanizável & 850 & 1.200 \\
Pastagem formada (Santarém/Belterra/Transamazônica) não mecanizável & 500 & 600 \\
Pastagem nativa em várzea (Monte Alegre/ Alenquer/Oriximiná) & 80 & 120 \\
Terra agrícola (Monte Alegre/Alenquer/Oriximiná) & 475 & 1.000 \\
Terra agrícola (Santarém/Belterra/Transamazônica) & 800 & 1.500 \\
Terra agrícola com café/cacau (Trairão/Ruropolis/Medicilândia) & 3.500 & 5.000 \\
\hline
\end{tabular}

Fonte: Retirada da Informa Economics América South-FNP (2011) reproduzida em: GAYOSO DA COSTA, S. Grãos na Floresta: estratégia expansionista do agronegócio na Amazônia. 2012. 322 f. Tese (Doutorado em Desenvolvimento Sustentável do Trópico Úmido) - Núcleo de Altos Estudos Amazônicos, Universidade Federal do Pará, Belém, 2012.

Livros de Registro Geral do Cartório do $1^{\circ}$ Oficio de Santarém, no período de 1997 a 2009, identificou-se a existência de 992 aberturas de novas matrículas, correspondentes aos imóveis rurais. Destas, 711 referem-se ao registro de títulos oriundos da Política de Reforma Agrária emitidos pelo INCRA, e 20 ao registro de Escrituras Públicas de Permuta, realizadas entre o governo estadual e particulares, com áreas da Gleba Nova Olinda. Conforme demonstrado na Tabela 5.
A pesquisa de imóveis registrados, realizada no Cartório do $1^{\circ}$ Oficio de Santarém, indicou a efetivação de 257 negócios, atingindo uma área total de $57.538,8507$ ha (Tabelas 6 e 7). No período de 1997-2000 são 17 negócios, envolvendo uma área de 1.158,3522 ha; no período de 20012005, 188 transações, com uma área de 17.266,5685 ha; e entre os anos de 2006-2009, 39.113,9300 ha foram negociados em 52 operações, envolvendo compra e venda, permutas e contratos de comodatos, conforme demonstrado na Tabela 6 .

Tabela 5 - Operações de registros cartoriais por ano: 1997-2009

\begin{tabular}{|c|c|c|c|}
\hline Ano & $\begin{array}{l}\text { Matrículas } \\
\text { criadas }\end{array}$ & $\begin{array}{l}\text { Registro de títulos da reforma } \\
\text { agrária }\end{array}$ & $\begin{array}{l}\text { Registro de escrituras públicas de permuta de } \\
\text { terras rurais }\end{array}$ \\
\hline 1997 & 40 & 32 & - \\
\hline 1998 & 37 & 30 & - \\
\hline 1999 & 32 & 26 & - \\
\hline 2000 & 45 & 25 & - \\
\hline 2001 & 70 & 26 & - \\
\hline 2002 & 139 & 78 & - \\
\hline 2003 & 178 & 138 & - \\
\hline 2004 & 112 & 96 & - \\
\hline 2005 & 72 & 67 & - \\
\hline 2006 & 41 & 36 & - \\
\hline 2007 & 70 & 59 & 02 \\
\hline 2008 & 101 & 50 & 17 \\
\hline 2009 & 55 & 48 & 1 \\
\hline Total & 992 & 711 & 20 \\
\hline
\end{tabular}

Fonte: Pesquisa no Cartório do $1^{\circ}$ Ofício, em Santarém/2010, apresentado em Gayoso da Costa (2012). 
Tabela 6 - Número de negócios por estrato de área na Região do Baixo Amazonas, de 1997-2009.

\begin{tabular}{|c|c|c|c|c|c|c|c|}
\hline \multirow{4}{*}{ Ano } & \multicolumn{6}{|c|}{ Número de Negócios } & \multirow{4}{*}{ Total } \\
\hline & \multirow{2}{*}{\multicolumn{2}{|c|}{$0<100$}} & \multicolumn{4}{|c|}{ Estrato de Área (ha) } & \\
\hline & & & & & $1000<$ & & \\
\hline & $\mathrm{N}$ & $\%$ & $\mathrm{~N}$ & $\%$ & & $\%$ & \\
\hline $1997-2000$ & 16 & 94,10 & 1 & 5,9 & - & & 17 \\
\hline 2001-2005 & 162 & 86,17 & 24 & 12,77 & 2 & 1,06 & 188 \\
\hline 2006- 2009 & 31 & 59,61 & 4 & 7,69 & 17 & 32,70 & 52 \\
\hline Total & 209 & 81,32 & 29 & 11,28 & 19 & 7,40 & 257 \\
\hline
\end{tabular}

Fonte: Pesquisa no cartório do $1^{\circ}$ Ofício, em Santarém/2010, apresentado em Gayoso da Costa (2012).

Tabela 7 - Área negociada por estrato de área na Região do Baixo Amazonas, de 1997-2009

\begin{tabular}{|c|c|c|c|c|c|c|c|}
\hline \multirow{4}{*}{ Ano } & \multicolumn{6}{|c|}{ Área de Negócios } & \multirow{4}{*}{$\begin{array}{c}\text { Total em } 1.000 \\
\text { ha }\end{array}$} \\
\hline & \multicolumn{6}{|c|}{ Estrato de Área (ha) } & \\
\hline & \multirow{2}{*}{\multicolumn{2}{|c|}{$N^{0<100}$}} & \multicolumn{2}{|c|}{$100<1.000$} & \multicolumn{2}{|c|}{$1.000<5.000$} & \\
\hline & & & $\mathrm{N}$ & $\%$ & & $\%$ & \\
\hline $1997-2000$ & $1.158,3522$ & 100 & & & & & $1.158,3522$ \\
\hline 2001-2005 & $6.855,2479$ & 39,70 & $5.065,2956$ & 29,33 & $5.346,0250$ & 30,97 & $17.266,5685$ \\
\hline 2006- 2009 & $1.146,6260$ & 2,93 & $1.749,3080$ & 4,48 & $36.218,0000$ & 92,59 & $39.113,9340$ \\
\hline Total & $9.160,2261$ & 15,92 & $6.814,6036$ & 11,84 & $41.564,0250$ & 72,24 & $57.538,8547$ \\
\hline
\end{tabular}

Fonte: Pesquisa no Cartório do $1^{\circ}$ Ofício, em Santarém/2010, apresentado em Gayoso da Costa (2012).

De acordo com os dados levantados, durante esse período de treze anos (1997-2009), preponderaram as transações de compra e venda de imóveis abaixo de 100 ha. Isso representou $81,32 \%$ do total de imóveis que foram objeto de compra e venda, correspondendo a uma área de $9.160,2261$ ha, equivalente a $15,92 \%$ do total da área negociada. Em contraposição, no estrato de 1.000 e mais hectares foram efetuados 19negócios, o que correspondeu a $7,40 \%$ do total,equivalendo a uma área de $41.564,0250$ ha, ou seja, $72,24 \%$ da área total negociada no período. Os negócios envolvendo o estrato de imóveis entre 100 e 1.000 ha corresponderam a 29 transações, isto é, $11,28 \%$ do total de imóveis, equivalente a $6.814,6036$ ha ou $11,84 \%$ do total de área (Tabela 7 ).

Os dados da pesquisa de imóveis registrados revelam a expressiva quantidade de negócios realizados envolvendo os imóveis abaixo de 100 ha, em sua totalidade, correspondendo a títulos emitidos pelo INCRA, fruto da Política de Colonização e ocupação da Amazônia. $O$ aumento do número de registros em cartório dos títulos emitidos pelo INCRA durante os referidos anos acompanhou o volume de transações de vendas realizadas no período. Isso indica que os produtores que chegaram à região do Baixo Amazonas compuseram o volume de terras necessário à produção de grãos, além das áreas acima de 100 ha, que foram objeto das investigações sobre grilagem, adquirindo vários imóveis com áreas menores que 100 ha, antes destinados à agricultura familiar. Como exemplo, destacamos 11 produtores migrantes das regiões Sul e Centro Oeste (Tabela 8), que utilizaram essa estratégia para aquisição de terras, e com ela conseguiram acumular áreas superiores a 100 ha, que corresponderam a cerca de $32,14 \%$ do total de áreas negociadas nesse estrato de imóveis. Isso explicita o processo de concentração de terras,próprio da atividade de produção da soja.

Os depoimentos dos produtores entrevistados confirmaram a concentração de terras, os quais possuem áreas entre 500 ha e mais de 1.000 ha, ainda não regularizadas, utilizadas na produção de grãos. Os entrevistados informaram, ainda, que a garantia da posse da terra foi dada pelo contrato de compra e venda: 
Tabela 8 - Área negociada por extrato de área e produtor na Região do Baixo Amazonas, de 1997-2009: imóveis abaixo de 100 ha.

\begin{tabular}{ccc}
\hline Produtor & $\begin{array}{c}\text { Número } \\
\text { de imóveis } \\
\text { negociados }\end{array}$ & $\begin{array}{c}\text { Volume de área } \\
\text { (ha) }\end{array}$ \\
\hline $\mathbf{0 1}$ & 11 & 516,1580 \\
$\mathbf{0 2}$ & 06 & 478,3903 \\
$\mathbf{0 3}$ & 05 & 294,7963 \\
$\mathbf{0 4}$ & 06 & 486,5339 \\
$\mathbf{0 5}$ & 05 & 177,6164 \\
$\mathbf{0 6}$ & 02 & 112,2748 \\
$\mathbf{0 7}$ & 02 & 116,5642 \\
$\mathbf{0 8}$ & 02 & 129,9776 \\
$\mathbf{0 9}$ & 02 & 192,0852 \\
$\mathbf{1 0}$ & 02 & 197,4789 \\
$\mathbf{1 1}$ & 08 & 242,5095 \\
\hline Total & $\mathbf{5 1}$ & $\mathbf{2 . 9 4 4 , 3 8 5 1}$ \\
\hline
\end{tabular}

Fonte: Pesquisa no Cartório do $1^{\circ}$ Ofício, em Santarém/2010, apresentado em Gayoso da Costa (2012).

[...] em Santarém somente 10\% têm a terra regularizada. Ninguém tem terra regularizada. A minha área eu tenho contrato de compra e venda, tenho o protocolo do INCRA, mas não posso regularizar a terra. São lotes menores de 100 ha que foram comprados pelo outro produtor de quem eu comprei. (Informação verbal) ${ }^{10}$.

Com essa estratégia, as fazendas de soja vão sendo ampliadas, pela aquisição de lotes contíguos ou fronteiriços, o que facilita a continuidade das áreas e a organização do sistema de plantio.

A pesquisa realizada possibilitou destacar os seguintes procedimentos utilizados pelos produtores de soja, na aquisição das terras dos assentados na região: 1) 0 produtor de soja instalado há mais tempo na região negocia a compra da terra para um novo produtor; 2) Uma vez que fecha as primeiras negociações, dirige-se ao cartório para a emissão da procuração de caráter irrevogável e irretratável, dando-lhe plenos poderes para alienar, vender, transmitir e proceder aos encaminhamentos junto aos órgãos oficiais para a quitação do imóvel; 3) De posse da procuração, o comprador vai até
- INCRA, quita a dívida com a UNIÃO, e solicita a certidão de quitação do imóvel; 4) De posse da certidão de quitação, vai até 0 cartório e faz-se 0 registro da certidão de quitação. A certidão de quitação cessa a condição anterior do imóvel rural financiado pelo INCRA. No levantamento realizado no cartório, das 257 operações de compra e venda de imóveis rurais, foram identificados 172 registros de certidões de quitação emitidas pelo INCRA ${ }^{11}$; 5) Examinando os dados do cartório, foi possível observar que, na maioria das operações realizadas no período de 2001 a 2005, após cerca de um ou dois meses (em alguns casos um pouco mais), o comprador volta ao cartório e faz a averbação da Escritura Pública de Compra e Venda na matrícula do imóvel, fato que concretiza a mudança de proprietário, na cadeia dominial do imóvel.

Outra situação observada em alguns registros foi que logo após a averbação da Escritura Pública de Compra e Venda foi feito o registro da hipoteca, resultado do empréstimo bancário junto ao Banco do Brasil ou ao BASA, ou ainda junto à Cargill. Outro tipo de estratégia utilizada como garantia da posse da terra é a manutenção do imóvel usando somente a procuração, ou seja, mantém-se a propriedade do imóvel com o contrato de compra e venda e com a procuração pública irrevogável e irretratável. Trata-se do uso de uma prática jurídica nos moldes do chamado contrato de gaveta, comumente utilizado nos casos de compra e venda de imóveis financiados pela política governamental habitacional urbana. No contrato de gaveta há a venda do imóvel, porém mantém-se $o$ financiamento ainda no nome do primeiro comprador. Contudo, no caso de imóvel rural, diferente do imóvel urbano, estando de posse da procuração e usando os esquemas de grilagem, pode-se pleitear a certidão de posse, o que permitirá o acesso ao financiamento para a produção de grãos.

\section{CONCLUSÃO}

A expansão da sojicultura na Amazônia constitui um processo de longa duração na consolidação dessa atividade econômica no Brasil, 
sendo que as áreas de fronteira agrícola representam uma alternativa para a sua expansão em larga escala. Os processos de indução da expansão da soja na região do Baixo Amazonas são extremamente fortes e contam com as vantagens competitivas que foram criadas com a implantação do porto da Cargill, e com a promessa de ampliação da infraestrutura e logística para o escoamento da produção. Há também o avanço no investimento tecnológico direcionado ao plantio da soja, que demonstrou ser uma atividade de alto poder competitivo, pelo fato de contar, na região, com um grande estoque potencial de terras, em razão da existência de grandes áreas devolutas e de terras não regularizadas, o que facilita a apropriação de ativos fundiários.

Além da disponibilidade de terras, outros fatores contribuíram para esse quadro, como a formulação de políticas públicas para abertura de novas áreas de terras destinadas ao plantio, financiamento, construção de estradas, instalação de portos, investimento em pesquisas, formação de mercado e preço das commodities em alta no mercado mundial. Portanto, o que se evidencia no processo de implantação da sojicultura na região amazônica é o efeito da produção de um ambiente (ou de um conjunto de relações sociais) que favorece e torna possível a sua consolidação, com processos que diferem em muito das demais culturas agrícolas tradicionalmente praticadas.

$\mathrm{Na}$ região do Baixo Amazonas, podese asseverar que as estratégias utilizadas pelos produtores de grãos, somadas às ações governamentais que visam o alardeado desenvolvimento sustentável, aglutinam interesses específicos, objetivando a consolidação dessa cultura agrícola na região, que tem como um de seus efeitos 0 aquecimento do mercado de terras e maior concentração fundiária nos municípios produtores.

Os dados da pesquisa de imóveis registrados revelam a expressiva quantidade de negócios realizados envolvendo os imóveis abaixo de 100 ha, que em sua totalidade correspondem a Títulos emitidos pelo INCRA, fruto da Política de Colonização e ocupação da Amazônia. Durante o período analisado, o aumento do número de registros de Títulos emitidos pelo INCRA em cartório acompanhou o volume de transações de vendas realizadas. Isso indica que os produtores de soja que chegaram à região do Baixo Amazonas compuseram o volume de terras necessário à produção de grãos, adquirindo vários imóveis com áreas menores que $100 \mathrm{ha}$, antes pertencentes a pequenos agricultores. Com essa estratégia, os produtores conseguiram acumular cerca de $30 \%$ do volume total de áreas negociadas nesse estrato de imóveis. Isso explicita o processo de concentração de terras, próprio da atividade de produção da soja. Como decorrência da expansão da soja na região houve uma elevada valorização das terras.

Esse aquecimento do mercado de terras tem levado ao aumento dos conflitos no campo, sendo as principais vítimas da disputa os povos e comunidades tradicionais que habitam as áreas de florestas preservadas. Também se encontram no centro dos conflitos os pequenos agricultores familiares que, pressionados pela produção de soja, têm sido expropriados de suas terras, pela pressão para a venda ou pela expulsão por meio de violência física. Em levantamento realizado entre maio de 2007 e junho de 2008, pelo Grenpeace, Sindicato dos Trabalhadores e Trabalhadoras Rurais de Santarém e Projeto Saúde Alegria, na região de Belterra e Santarém, foram identificadas 27 comunidades reduzidas e duas extintas, em função das plantações de soja.

Levando-se em conta o estoque de áreas existentes e 0 aquecimento dos mercados de terras e madeireiro, pode-se vislumbrar que a pressão sobre as terras do Baixo Amazonas continuará colocando em risco a sobrevivência dos agricultores familiares, povos e comunidades tradicionais da Amazônia. Soma-se a isso, a posição estratégica da Região Norte para o escoamento da produção de grãos, o que potencializa ainda mais a pressão sobre as terras nas áreas analisadas. 


\section{REFERÊNCIAS}

ALMEIDA, L. M. de et al. Arranjos produtivos de grãos na região de influência do município de Santarém no Estado do Pará. 2006. 40 f. Trabalho de Conclusão de Curso (Especialização) - Instituto de Ciências Sociais Aplicadas, Universidade Federal do Pará, Belém, 2006.

BRASIL. Ministério da Agricultura, Pecuária e Abastecimento. Assessoria de Gestão Estratégica. Projeções do agronegócio Brasil 2010/11 a 2020/21. Brasília, DF, 2011.

CASTILHO, M. W; CASTRO, J. G. D. Do sertão à periferia: a expropriação camponesa pela expansão da soja: o caso da Serra do Centro em Campos Lindos. Tocantins: FASE, 2005.

CASTRO, E. Políticas de ordenamento territorial, desmatamento e dinâmicas de fronteira. Novos Cadernos NAEA, Belém, v. 10, n. 2, p. 105-126, dez. 2007.

; MONTEIRO, R. Setor madeireiro, dinâmica de atores e política florestal. In: VENTURIERI, A. (Ed.). Zoneamento Ecológico-Econômico da área de influência da Rodovia da BR-163 (CuiabáSantarém): gestão territorial - diagnóstico do meio socioeconômico, jurídico e arqueologia. v. 1. Belém: EMBRAPA Amazônia Oriental, 2007, p. 168-200.

CASTRO, C. P. Estudo sobre dinâmicas sociais na fronteira, desmatamento e expansão da pecuária na Amazônia: relatório técnico. Belém: Banco Mundial, 2002.

COMISSÃO PASTORAL DA TERRA. Relatório do levantamento preliminar dos impactos socioambientais da expansão da agricultura mecanizada na região de Santarém. Santarém, 2004.

COSTA. F. de A. Trajetórias tecnológicas, territórios e mercado de terras na Amazônia. In: SAUER, S.; ALMEIDA, W. (Org). Terras e territórios na Amazônia: demandas, desafios e perspectivas. Brasília, DF: EDUnB, 2011.
, F. G. Avaliação do potencial de expansão da soja na Amazônia legal: uma aplicação do modelo de Von Thünen. 2000. 162 f. Dissertação (Mestrado em Agricultura) - Escola Superior de Agricultura Luiz de Queiroz, Universidade de SãoPaulo, Piracicaba, 2000.

EMPRESA BRASILEIRA DE PLANEJAMENTO DE TRANSPORTES. Corredores estratégicos de desenvolvimento: relatório final. Brasília, 1999. Disponivel em; <GEIPOT:http://www.geipot.gov.br/>. Acesso em: 13 abr. 2012.

GAYOSO DA COSTA, S. Agronegócio e terras na Amazônia: conflitos sociais e desterritorialização após a chegada da soja na região do Baixo Amazonas no Pará. In: SAUER, S.; ALMEIDA, W. (Orgs.). Terras e territórios na Amazônia: demandas, desafios e perspectivas. Brasília: Brasília, DF: EDUnB, 2011. p. 69-89.

. Grãos na Floresta: estratégia expansionista do agronegócio na Amazônia. 2012. 322 f. Tese (Doutorado em Desenvolvimento Sustentável do Trópico Úmido) - Núcleo de Altos Estudos Amazônicos, Universidade Federal do Pará, Belém, 2012.

INFORMA ECONOMICS AMERICA SOUTH-FNP. Relatório de Análise do mercado de terras. São Paulo, 2011. (Relatório bimestral, n. 39).

INSTITUTO BRASILEIRO DE GEOGRAFIA E ESTATÍSTICA. Censo agropecuário 2006. Rio de Janeiro, 2007.

Banco de Dados Agregados. Rio de Janeiro, [20--?]. Disponível em:<http://www.sidra. ibge.gov.br/bda.>Acesso em: 25 ago. 2011.

LIMA, M. do S. B. de. Políticas públicas e território: uma discussão sobre os determinantes da expansão da soja no sul do amazonas. 2008. 446 f. Tese (Doutorado em Desenvolvimento, Agricultura e Sociedade) - Universidade Federal Rural do Rio de Janeiro, Rio de Janeiro, 2008.

MIRANDA, R. S. Conflitos socioambientais e processos de territorialização no sul do Maranhão. In: 
CONGRESOLATINOAMERICANODE SOCIOLOGÍA RURAL, 8., 2010, Pernambuco. Anais... Pernambuco: ALASRU, 2010. Disponível em:<http://www.alasru. org/wp-content/uploads/2011/07/GT7-Roberto-deSousa-Miranda.pdf>. Acesso em: 12 out. 2011.

PARÁ. Secretaria Estadual de Desenvolvimento Agropecuário e de Pesca. Dados Agropecuários. Belém, 2012. Disponível em:<http://www.sagri. pa.gov.br/>. Acesso em: 21 nov. 2011.

PUTY, C.A. C. B. Agricultura Empresarial Mecanizada. In: VENTURIERI, A. (Ed.). Zoneamento EcológicoEconômico da área de influência da Rodovia da BR-163 (Cuiabá-Santarém): gestão territorial. Diagnóstico do meio socioeconômico, jurídico e arqueologia. v. 1. Belém: EMBRAPA Amazônia Oriental, 2007, p. 229-252.

NOTAS

${ }^{1}$ Os dados aqui apresentados foram obtidos durante a pesquisa e elaboração da tese de doutorado da autora, defendida em junho de 2012, no Núcleo de Altos Estudos Amazônicos (NAEA/UFPA), intitulada Grãos na floresta: estratégia expansionista do agronegócio na Amazônia.

${ }^{2}$ Amazônia Legal compreende os estados do Acre, Amapá, Amazonas, Mato Grosso, Pará, Rondônia, Roraima, Tocantins e parte do Maranhão.

${ }^{3}$ Desmembrado do município de Santarém, o município de Mojuí dos Campos, criado em 1999, teve sua primeira eleição somente em 2012, ano em que de fato passou a ter uma organização administrativa municipal. Em decorrência disso, todos os dados sobre a produção agrícola desse município ainda são considerados como do município de Santarém.

${ }^{4}$ Esta estratégia foi utilizada por produtores de soja nos municípios do Baixo Amazonas, sendo identificada quando examinamos os registros do Cartório do $1^{\circ}$ Oficio Nogueira Sirotheau, em Santarém.

${ }^{5} \mathrm{~A}$ introdução do milho e do arroz, como uma etapa anterior, permite a preparação total do solo para o cultivo mecanizado em terrenos que ainda não estejam totalmente limpos dos restos de florestas. Ambas as culturas apresentam um custo menor de produção, assim como requerem uma menor extensão de terra. Dessa forma, o milho e 0 arroz acabam financiando também o cultivo da soja, uma vez que essas culturas "amansam" o solo através do aplainamento exigido pelo tipo de mecanização associadas "[...] às reduzidas proporções da própria planta de soja, quando garantem a capitalização para o investimento em maior escala por parte dos médios produtores." (PUTY, 2007, p. 242).

${ }^{6}$ Entrevista realizada com E. M., liderança sindical.

${ }^{7}$ Depois de seis anos de alta nos preços, em novembro de 2005, no estado do Paraná, a cotação era de $R \$ 27,90$, 0 mais baixo nível desde maio de 2003 . O processo de queda nos preços foi deflagrado em junho de 2004, quando a média ficou em $R \$ 44,00$. Desde lá, o preço médio nunca mais rompeu a barreira dos $\mathrm{R} \$ 40,00$. Ao contrário, caiu, ficando abaixo dos $R \$ 30,00$ a partir de setembro de 2005 .

${ }^{8}$ Sobre as formas e percentuais de apropriação dos outros extratos, ver Costa $(2009 ; 2011)$.

${ }^{9}$ Informa Economics FNP é o novo nome que a Agra FNP passou a ter desde janeiro de 2011. A ação é parte do processo de integração com a Informa Economics, empresa de consultoria e informação para o agronegócio nos Estados Unidos, Europa e agora na América do Sul, pertencente à Informa Group (FNP, 2011).

${ }^{10}$ Entrevista realizada com A. N. em 27 de agosto de 2010.

11 Corresponde ao número de averbações de certidões de quitação explicitamente identificadas na ficha de matrícula dos imóveis. Foi observado que em algumas operações de compra e venda envolvendo Títulos emitidos pelo INCRA, não constavam da ficha de matrícula a averbação da certidão de quitação. Havia o registro do título, e posteriormente 0 registro da Escritura Pública de Compra e Venda, acrescido, em alguns casos, da observação de que o título estava devidamente quitado.

\section{Solange Maria Gayoso da Costa}

Assistente Social

Doutora em Ciências Socioambientais pelo Programa de PósGraduação em Desenvolvimento Sustentável do Trópico Úmido (NAEA/UFPA)

Professora do Programa de Pós-Graduação em Serviço Social (PPGSS) do Instituto de Ciências Sociais Aplicadas (ICSA) da Universidade Federal do Pará (UFPA)

E-mail: solgayoso@ufpa.br

Universidade Federal do Pará - UFPA

Instituto de Ciências Sociais Aplicadas - Avenida Augusto Corrêa 01 - Guamá

CEP: $66075-110$ 